\title{
Pemberdayaan Perempuan Melalui Pelatihan Menjahit di Desa Sukosono Jepara
}

\author{
Hardiyanto Hadiputra ${ }^{1}$, Azzah Nor Laila ${ }^{2}$, Lutfiyanti Axmi Reza ${ }^{3,}$ Desi Maila Fira ${ }^{4}$ \\ 1,2,3,4 Program Studi Pendidikan Agama Islam,UNISNU \\ E-mail: 'hardiputra092@gmail.com, ${ }^{2}$ azzah@unisnu.ac.id, ${ }^{3}$ lutfiyantiaxmireza07@gmail.com \\ 4viravaro4@gmail.com
}

\begin{abstract}
Abstrak
Pandemi Covid-19 memiliki dampak lemahnya ekonomi keluarga, banyaknya pekerja diberhentikan, dan usaha tidak berjalan maksimal. Pada sisi lain kelompok ibu-ibu memiliki waktu luang, potensi untuk produktif secara mandiri dengan usaha dari rumah, namun belum memiliki ketrampilan. Maka untuk mengatasi permasalahan tersebut tim pengabdi melakukan kegiatan pengabdian pelatihan menjahit. Kegiatan pengabdian ini bertujuan memberdayakan perempuan, meningkatkan kreatifitas, dan kemandirian perempuan di desa Sukosono Kecamatan Kedung Kabupaten Jepara. Metode pengabdian ini adalah sosialisasi, pelatihan, dan pendampingan menjahit yang meliputi pembuatan pola, pemotongan, dan menjahit. Kegiatan pengabdian ini dilakukan secara tatap muka atau luring dengan tetap mematuhi protokol kesehatan. Pelatihan menjahit dilakukan dengan beberapa tahapan. Pertama, peserta dilatih membuat pola dengan media kertas karton lalu diterapkan pada kain. Kedua, peserta diajari memotong kain dengan baik. Ketiga, peserta dilatih menjahit dengan teknik yang benar, sehingga hasilnya rapi. Bahan kain yang digunakan kain tenun Troso, agar peserta nantinya mampu memanfaatkan bahan produk lokal Jepara. Respon peserta terhadap pengabdian ini menunjukkan pada aspek materi 95\% menilai sangat baik, aspek fasilitator $90 \%$ menilai sangat baik, dan selebihnya merespon baik. Hasil pengabdian ini menunjukkan $85 \%$ peserta berhasil terampil dalam menjahit, dilihat dari keberhasilan peserta membuat rintisan usaha jasa menjahit, dan konveksi dari bahan kain setelah mengikuti kegiatan pengabdian.
\end{abstract}

Kata kunci: Pemberdayaan, Perempuan, Menjahit, Kreatif, Mandiri

\begin{abstract}
The Covid-19 pandemic has an impact on the weak economy of families, many workers have been laid off, and businesses are not running optimally. On the other hand, the group of mothers has free time, the potential to be productive independently by working from home, but they do not have the skills. So to overcome these problems the service team carried out sewing training service activities. This service activity aims to empower women, increase creativity, and independence of women in Sukosono, Kedung, Jepara.. This service method is socialization, training, and sewing assistance which includes pattern making, cutting and sewing. This service activity is carried out face-to-face or offline while adhering to health protocols. Sewing training is carried out in several stages. First, participants are trained to make patterns using cardboard paper and then apply them to the fabric. Second, participants are taught to cut cloth properly. Third, participants are trained to sew with the correct technique, so that the results are neat. The fabric used is Troso woven cloth, so that participants will be able to use Jepara's local products. The response of the participants to this dedication showed that in the material aspect 95\% considered it very good, $90 \%$ of the facilitator aspect considered it very good, and the rest responded well. The results of this dedication showed that $85 \%$ of the participants were successful in sewing skills, seen from the success of the participants in making a sewing service business start-up and convection from fabric after participating in service activities..
\end{abstract}




\section{PENDAHULUAN}

Secara historis, perempuan memiliki posisi tersendiri yang istimewa. Terkadang posisi seorang perempuan selalu diperdebatkan kedudukannya, hingga berkaitan kepada masalah kesetaraan gender. Perempuan memiliki porsinya masing-masing dalam berbagai perspektif, namun secara umum perempuan memiliki kedudukan penting yang patut untuk diperhitungkan, bahkan dalam skala besar. Hal ini sejalan dengan ketentuan PBB dalam Millenium Development Goals (MDG) yang membicarakan mengenai kesetaraan gender dan pemberdayaan perempuan [1]. Ketentuan tersebut menegaskan bahwa perempuan seharusnya memiliki peran yang besar dalam setiap pembangunan bangsa.

Pada abad ke-21 manusia dituntut untuk dapat terus menciptakan inovasi- inovasi baru dalam segala bidang yang ditandai dengan adanya revolusi industri 4.0. Melalui revolusi industry setiap manusia disadarkan bahwa siapapun harus bergerak dan bersiap dengan segala perubahan yang akan terjadi, termasuk perempuan. Salah satu sektor utama dalam usaha untuk mengupayakan tercapainya revolusi industri adalah dengan adanya peningkatan ekonomi. Dalam bidang ekonomi perempuan cenderung mengalami krisis diskriminatif dari lak-laki. Beberapa pekerja perempuan menerima upah kerja yang lebih rendah daripada laki-laki, sehingga perempuan perlu merubah mindset mengenai mental pekerja menjadi mental pengusaha [2]. Perempuan memiliki kesempatan yang sama dengan laki- laki untuk menciptakan dunianya sendiri dan ikut andil dalam perekonomian termasuk dalam bidang Usaha Mikro Kecil dan Menengah (UMKM).

Di Indonesia sektor UMKM menjadi primadona dalam bidang usaha. Dimana sekitar $99,99 \%$ adalah pengusaha berskala kecil dan sisanya yakni $0,01 \%$ adalah pengusaha berskala besar. Pengembangan ekonomi untuk perempuan tidak dapat berjalan dengan baik tanpa adanya kegiatan pemberdayaan yang sesuai dengan bidang mereka [3]. Jepara sebagai salah satu kota di Indonesia yang menyimpan banyak potensi dari masyarakatnya dalam bidang ekonomi dan sosial. Salah satu pusat kegiatan ekonomi masyarakat Jepara adalah pasar, di mana melalui pasar UMKM berkembang pesat. Melalui UMKM, ekonomi masyarakat Jepara berkembang menjadi beberapa sektor yang unik yang dimiliki oleh berbagai sentra industri kerajinan di berbagai desa. Setiap desa di Kabupaten Jepara memiliki ciri khasnya masing-masing, termasuk dalam bidang home industry [4].

Desa Sukosono sebagai salah satu desa di Kabupaten Jepara merupakan sebuah desa yang terletak di ujung utara Kecamatan Kedung. Terletak pada $9 \mathrm{~km}$ sebelah selatan Kota Jepara. Berdasarkan data statistik penduduk tahun 2007, penduduk Desa Sukosono berjumlah sebanyak 5.560 jiwa, terdiri atas 2.779 jiwa laki - laki dan 2.781 jiwa perempuan, dengan ratarata $48 \%$ bekerja sebagai tani, $40 \%$ sebagai tukang kayu, $12 \%$ bekerja sebagai buruh, karyawan, wiraswata, dan lain-lain. Jumlah penduduk perempuan di desa Sukosono tergolong dalam jumlah besar. Dimana menurut statistik jumlahnya melebihi penduduk laki- laki.

Para perempuan di desa Sukosono sebagian besar berprofesi sebagai ibu rumah tangga, padahal banyak potensi yang dapat dioptimalkan dari perempuan. Oleh karena itu, para perempuan juga perlu dibekali dan dibimbing secara langsung dengan ketrampilan baru. Sehingga para perempuan di desa Sukosono mampu bergerak dan meningkatkan keterampilannya untuk membantu dalam bidang ekonomi keluarga. Para perempuan dapat menciptakan lapangan kerjanya sendiri, mengingat sebesar $40 \%$ pekerja adalah tukang kayu yang didominasi oleh lelaki, dan $48 \%$ adalah petani yang ditekuni oleh mayoritas laki- laki dan sedikit dari perempuan.

Akhir- akhir ini marak penajajahan industri melalui pabrik konveksi milik asing. Para perempuan cenderung menghabiskan waktunya untuk bekerja di luar lingkungannya. Melalui kegiatan pemberdayaan bersama organisasi perempuan di desa Sukosono, tim pengabdi berusaha mengupayakan pemecahan atas permasalahan tersebut melalui kegiatan pengabdian 
pelatihan menjahit. Dunia konveksi identik dengan perempuan, dimana konveksi sendiri dikenal dengan CMT (Cut, Make, and Trim) yaitu kegiatan memotong kain, membuat atau mengolah kain yang meliputi kegiatan menjahit, dan desain akhir pada kain yang sudah terolah [5]. Dengan adanya kegiatan pemberdayaan ini diharapkan bahwa para perempuan di desa Sukosono dapat mengembangkan sendiri bisnisnya dari rumah (home industry) sebagai bentuk peningkatan ekonomi masyarakat.

\section{METODE}

Kegiatan pengabdian pemberdayaan perempuan di Desa Sukosono ini dilakukan di gedung Muslimat NU Sukosono, kecamatan Kedung, kabupaten Jepara. Peserta program ini adalah perempuan penduduk desa Sukosono usia produktif di desa Sukosono yang berjumlah sepuluh orang peserta. Pelatihan dilakukan dengan beberapa tahapan, yaitu:

a. Sosialisasi kegiatan di desa Sukosono

b. Penyampaian materi mengenai pembuatan pola kain

c. Penyampaian materi memotong kain dan menjahit

e. Pendampingan praktik membuat pola, memotong kain, dan menjahit.

Kegiatan pemberdayaan perempuan melalui kegiatan menjahit ini berupa pelatihan pembuatan pola, pemotongan kain dan menjahit yang dilakukan di Gedung Muslimat NU Sukosono Kedung Jepara. Mitra dalam kegiatan ini adalah kelompok perempuan desa Sukosono, pemilihan mitra telah ditentukan dengan melalui kegiatan observasi secara langsung. Dengan melihat pada kondisi kurangnya pemberdayaan perempuan terutama dalam bidang ekonomi dan pendidikan. Kompetensi yang diajarkan meliputi pembuatan pola pada kain, memotong pola yang terbentuk pada kain dan menjahit kain.

Tim pengabdi telah mempersiapkan secara matang kegiatan pemberdayaan perempuan dalam bidang konveksi ini. Dengan menghadirkan pemateri serta fasilitas yang memadai. Guna mencapai kepuasaan dan kebermanfaatan hasil yang maksimal bagi mitra.

\section{HASIL DAN PEMBAHASAN}

Kegiatan pelatihan menjahit dilakukan dengan beberapa rangkaian, mulai pelatihan pembuatan pola, pemotongan, dan menjahit. Kondisi masa pandemi covid 19 masih terus diwaspadai dan dicegah penyebarannya, maka kegiatan pengabdian dilakukan dengan pembatasan peserta serta sesuai protokol kesehatan. Peserta kegiatan ada $10 \mathrm{ibu}$ rumah tangga, perwakilan dari Rt tertentu yang benar-benar minat dan memiliki keinginan untuk menuju produktif.

Pada pertemuan pertama tanggal 25 Februari 2021, materi pelatihan fokus pada pembuatan pola dengan narasumber Hardiyan Hadiputra. Peserta diajari tentang menggambar dan membuat pola dengan media kertas, alat tulis pensil dan spidol. Peserta antusias dan semangat mengikuti pelatihan dan praktek pembuatan pola sebagaimana pada Gambar 2. 


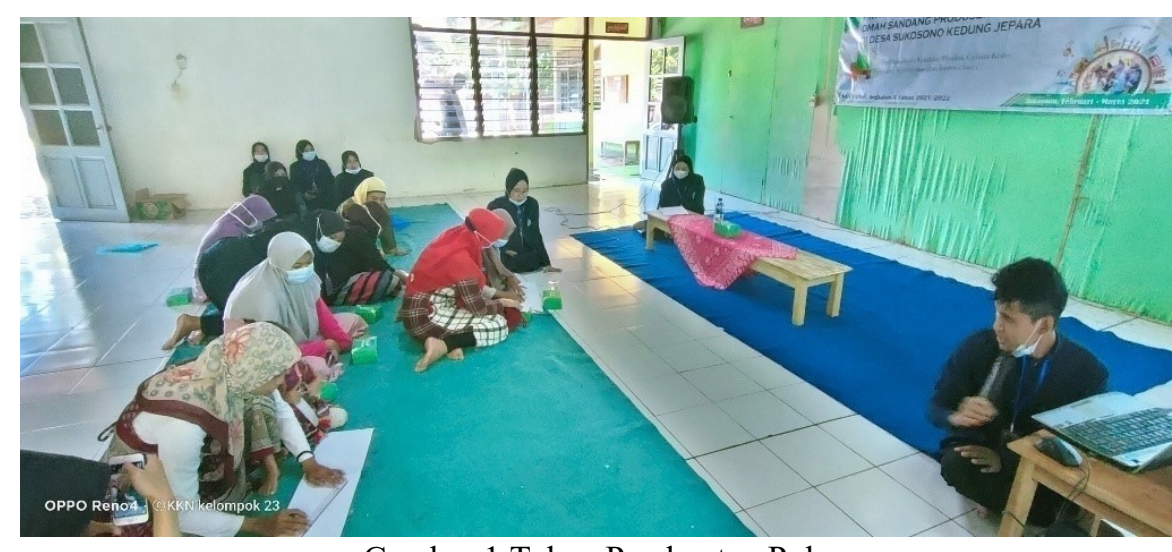

Gambar 1 Tahap Pembuatan Pola

Selanjutnya pada tanggal 26 Februari 2021, dilanjutkan pelatihan penerapan pola pada kain dan pemotongan. Kegiatan kedua ini dipandu oleh fasilitator Lutfiyanti Axmi Reza. Para peserta dibagi menjadi tiga kelompok, dimana masing-masing kelompok diberi satu lembar kain tenun Troso. Setiap kelompok diajari menerapkan pola yang sudah digambar pada kain, kemudian diberi gambar atau tanda pada kain, lalu dipotong. Peserta meskipun dibagi kelompok, namun masing-masing mencoba melakukan praktek secara bergantian. Pelaksanaan pada tahap penerapan pola dan pemotongan kain sebagaimana pada Gambar 3.

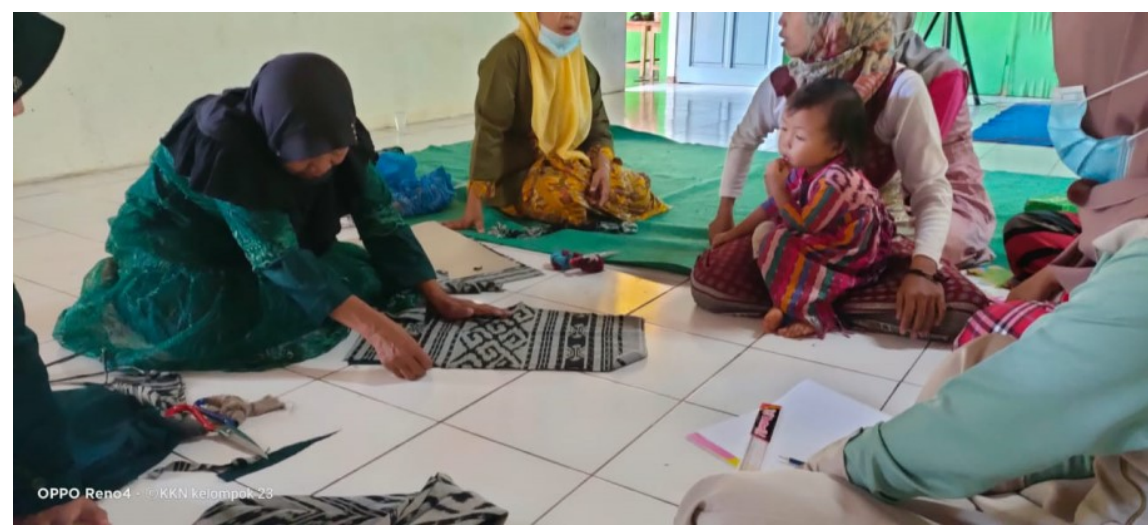

Gambar 2 Tahap Penerapan Pola Pada Kain dan Pemotongan

Pertemuan ketiga adalah pelatihan inti yakni menjahit, yang terlaksana pada hari ketiga tanggal 27 Februari 2021. Peserta sesuai kelompok diajari teknik menjahit yang benar dan baik. Kemudian peserta juga dilibatkan praktek menjahit secara bergantian. Peserta tampak antusias dan aktif mengikuti arahan dari pemateri. Para peserta mencoba mempraktekkan sendiri secara langsung dalam menggunakan mesin jahit portable. Dalam pelatihan menjahit pemateri tetap mendampingi peserta satu- satu secara bergantian. Peserta diajari bagaiman menjahit pola yang telah mereka buat sebelumnya. 


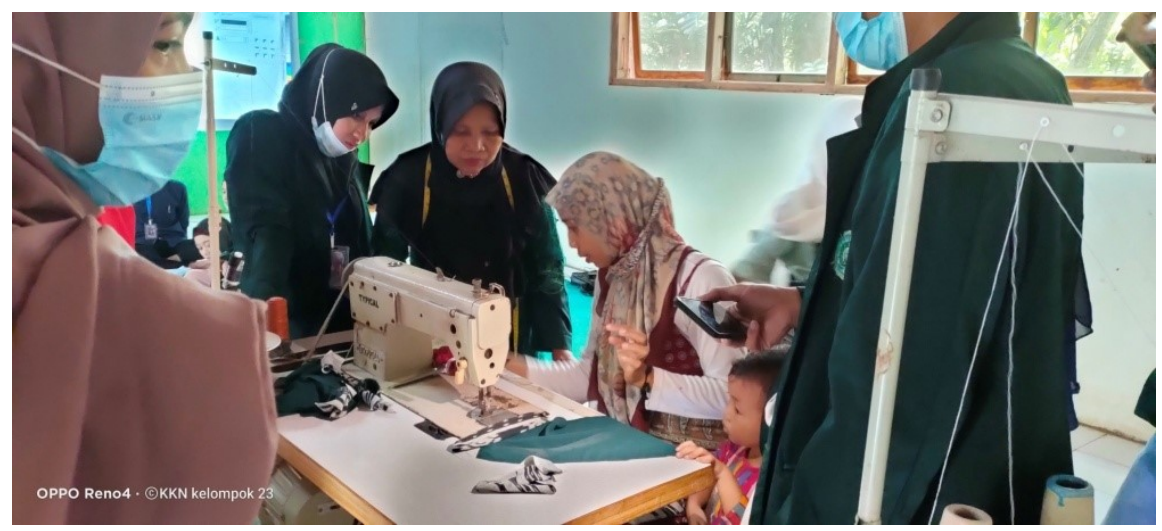

Gambar 3 Tahap Menjahit

Pada akhir kegiatan para peserta diminta untuk mengisi kuesioner terkait dengan kegiatan pengabdian yang telah dilakukan. Hasil dari kuesioner peserta dapat dilihat pada Gambar 4.

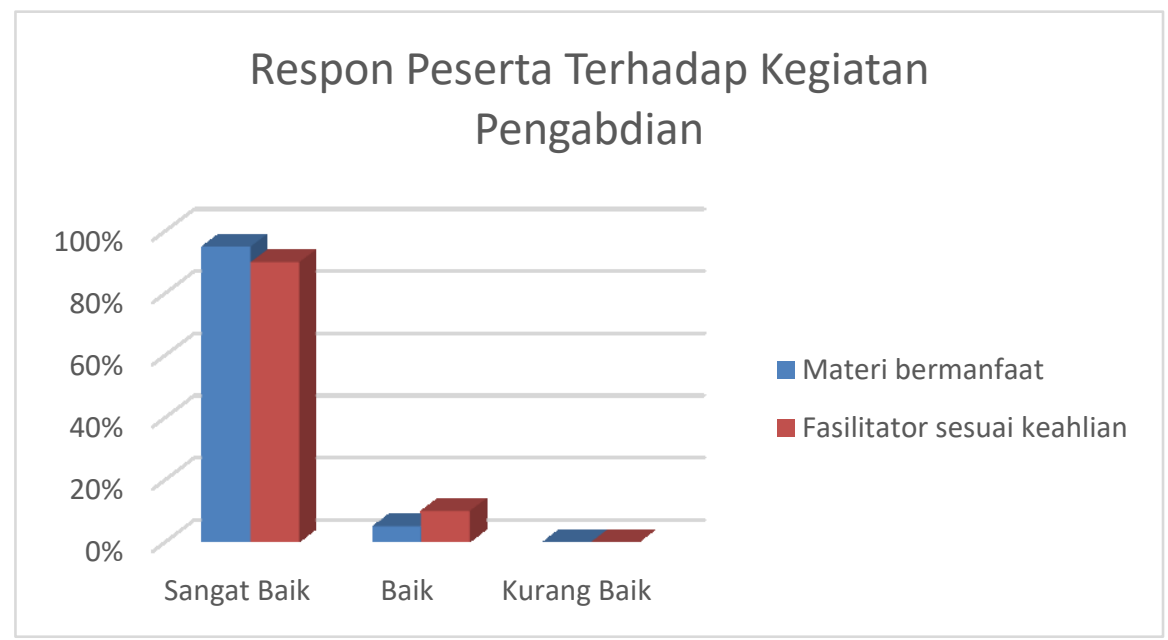

Gambar 4 Grafik Hasil Respon Peserta

Gambar 4 tersebut menunjukkan rata-rata respon peserta menilai baik materi maupun fasilitator pada kegiatan pengabdian ini sangat baik. Pada aspek materi bermanfaat $95 \%$ peserta merespon sangat baik, dan 5\% baik. Pada aspek fasilitator sesuai keahlian menunjukkan $90 \%$ peserta merespon sangat baik, dan $10 \%$ merespon baik. Hal itu berarti secara umum peserta puas terhadap program pengabdian ini, dan tidak ada yang memilih opsi kurang baik.

\section{KESIMPULAN DAN SARAN}

Kegiatan pengabdian pembeerdayaan perempuan di desa Sukosono dilakukan demi terwujudnya home industri dalam bidang konveksi sebagai bentuk peningkatan skill dan pengetahuan dari para peserta yang didominasi oleh ibu- ibu. Dengan tetap mematuhi protokol kesehatan kegiatan pemberdayaan perempuan ini dapat berjalan dengan kondusif. Pemberdayaan perempuan melalui bidang konveksi yang meliputi pembuatan pola, pemotongan dan menjahit pola dapat dipraktikan oleh semua peseta secara mandiri dengan baik. Kegiatan pemberdayaan ini juga dinilai dapat membawa manfaat bagi para peserta. Sekaligus kegiatan ini dapat direalisasikan nantinya sebagai bentuk keberlanjutan secara mandiri. 


\section{UCAPAN TERIMA KASIH}

Penulis mengucapkan terima kasih kepada Rektor Universitas Islam Nahdlatul Ulama (UNISNU) Jepara dan Ketua Lembaga Penelitian dan Pengabdian Masyarakat (LPPM) UNISNU Jepara yang telah mendukung kegiatan ini. Baik dukungan secara finansial maupun motivasi, sehingga kegiatan ini terlaksana secara keseluruhan dan lancar.

\section{DAFTAR PUSTAKA}

[1] Zakiyah. 2010. Pemberdayaan Perempuan oleh Lajnah Wanita dan Putri Al- Irsyad Surabaya. Jurnal Analisa. Volume XVII. No. 01, hlm 37-56

[2] Kusumahadi, Didik. 2012. Efektifitas Pelaksanaan Pemberdayaan Perempuan dan Dampaknya Terhadap pola kesejahteraan masyarakat. Jurnal Reformasi. Volume 2. No. 2, hlm 103-108

[3] Suci, Yuli Rahmini. 2017. Perkembangan UMKM (Usaha Mikro Kecil Menengah) di Indonesia. Jurnal Ilmiah Cano Economos. Volume 6. No. 01, hlm 51-58

[4] Najah, A \& Malarsih,M. 2019. Pelestarian Tari Pesta Baratan di Kecamatan Kalinyamatan Kabupaten Jepara. Jurnal Seni Tari.dikases dari https://doi.org/10.15294/jst.v8i1.30770

[5] Haryono, Tulus, dkk. Akselerasi Bisnis Konveksi Batik Melalui Manajemen Industri Kreatif di Surakarta. Cakra Wisata. Volume 17. Jilid 1, hlm 1-19 